\title{
Bilateral Facial Paralysis Following Ethylene Glycol Ingestion
}

\author{
K.B. Mallya, T. Mendis, and A. Guberman
}

\begin{abstract}
Bilateral facial weakness, diminished hearing and dysphagia developed in a patient with a large overdose of ethylene glycol. Our case and two others previously reported draw attention to the fact that cranial nerve dysfunction, especially bilateral facial palsy, may occur in addition to encephalopathy, coma and renal failure with ethylene glycol ingestion.
\end{abstract}

RÉSUMÉ: Paralysie faciale bilatérale à la suite de l'ingestion d'éthylène glycol A la suite de l'ingestion d'une dose excessive d'éthylène glycol, un patient a développé de la faiblesse faciale bilatérale, une diminution de l'acuité auditive et de la dysphagie. Notre cas ainsi que deux autres rapportés antérieurement, attirent l'attention sur le fait qu'une dysfonction des nerfs crâniens, particulièrement une paralysie faciale bilatérale, peut survenir en plus de l'encéphalopathie, du coma et de l'insuffisance rénale à la suite de l'ingestion d'éthylène glycol.

Can. J. Neurol. Sci. 1986; 13:340-341

Ethylene glycol is widely used as an antifreeze substance for automobile engines. Several reports have described the effects of ethylene glycol ingested either as a substitute for ethanol or for attempted suicide. ${ }^{1-9}$ Renal and cardiopulmonary consequences following ingestion of ethylene glycol have been well documented but neurological sequelae have only rarely been observed. ${ }^{7,8}$ Bilateral facial paralysis as well as less striking bilateral involvement of cranial nerves VIII and IX occurred as neurological consequences of ethylene glycol ingestion in the case reported here.

\section{CaSe Report}

A 26 year old man in excellent past health, was hospitalized following ingestion of approximately $200 \mathrm{ml}$ of antifreeze ( $95 \%$ ethylene glycol) in a suicide attempt 11 days prior to admission. He developed severe nausea and vomiting and one week later became anuric. The only neurological complaint on admission was left-sided facial "numbness". A few days later he noted difficulty drinking from a straw and chewing his food as well as closing his eyes.

On examination the patient was found to be alert and oriented with blood pressure $130 / 90 \mathrm{~mm}$ of $\mathrm{Hg}$, pulse rate 98 per minute, temperature $37.2^{\circ} \mathrm{C}$, respiratory rate $28 / \mathrm{min}$. General physical and neurological examination were normal apart from a few bruises on his forehead, pupils sluggishly reactive to light and the presence of bilateral facial paralysis with inability to close his eyes completely, loss of forehead wrinkling and lower facial movements and loss of taste to salt or sugar on the anterior tongue bilaterally. Taste testing was not carried out over the posterior one-third of the tongue. Olfaction was intact to a bar of soap. Visual acuity was 20/20 bilaterally. Extraocular movements were full without nystagmus. There was normal sensation over the face and corneas and good masseter strength. Hearing, palatal and tongue movements were normal. Deep tendon reflexes were brisk throughout. Gait was normal and no ataxia was noted. Blood biochemistry revealed: serum sodium $138 \mathrm{mEq} / \mathrm{L}$; potassium $4.2 \mathrm{mEq} / \mathrm{L}$; chloride $108 \mathrm{mEq} / \mathrm{L}$; bicarbonate $10 \mathrm{mEq} / \mathrm{L}$; BUN $47.1 \mathrm{mmol} / \mathrm{L}$; creatinine $3016 \mathrm{mmol} / \mathrm{L}$. Arterial blood gas results revealed: $\mathrm{pH} 7.21 ; \mathrm{pCO}_{2} 26 \mathrm{~mm} \mathrm{Hg} ; \mathrm{pO}_{2} 91$ $\mathrm{mm}$ of $\mathrm{Hg}$. Skull $\mathrm{x}$-rays and unenhanced CT scan of the head were normal. Blink reflexes could not be recorded and direct facial nerve stimulation was not performed because the patient refused. Brainstem auditory evoked responses showed normal interpeak latencies but latencies of responses were increased on both sides and behaviour thresholds to clicks were $50 \mathrm{~dB}$ in the right ear and $35 \mathrm{~dB}$ in the left ear. This was felt to be consistent with bilateral peripheral neurosensory hearing loss. Formal audiological testing was not done. A week following admission to hospital the patient complained of some difficulty in swallowing and also some hearing difficulty. On examination he was found to have an absent gag reflex bilaterally. The palate elevated poorly but there was no hoarseness of voice. Renal failure was treated by hemodialysis and the patient was discharged home after 22 days. Prior to discharge there was some improvement in swallowing and pupillary light reflexes had returned to normal but only slight facial movement was detectable. One year later, moderate facial weakness remained, the patient could not close his eyes completely, and he had difficulty eating.

\section{Discussion}

Ethylene glycol when ingested is rapidly absorbed from the stomach and quickly converted by the liver to toxic aldehydes, oxolates and lactic acid. ${ }^{9}$ The initial picture is evident within thirty minutes to twelve hours following ingestion and may mimic ethanol intoxication. ${ }^{3}$ If untreated rapid progression to 
stupor, coma and death usually occurs. The second stage of cardiopulmonary symptoms at 24 to 72 hours consists of hypotension, cardiac arrhythmias, metabolic acidosis, cyanosis, pulmonary edema and possible bronchopneumonia. ${ }^{3}$ If the patient survives the first two stages symptoms of renal failure ranging from proteinuria to anuria supervene. ${ }^{3}$

Our patient had reached the stage of renal failure by the time he was hospitalized and never developed cardiopulmonary complications. Initially his bilateral marked facial paralysis was thought to be of traumatic origin. It then became apparent that he had not suffered sufficient facial trauma to account for it and evidence of bilateral impairment of eighth and ninth cranial nerves also appeared. Various neurological sequelae have been reported in survivors of ethylene glycol intoxication $1,2,5,7,8$ but bilateral facial paralysis has been described only twice before. $^{7.8}$

Ethylene glycol can produce unusual focal neurological findings in addition to ataxia, tremors, encephalopathy, seizures and coma. The resulting facial weakness may be permanent, as appears to be the case in our patient. The mechanism of cranial nerve damage remains unknown.

\section{REFERENCES}

1. Pons CA, Custer RP. Acute ethylene glycol poisoning. Amer J Med Sci 1946; 211: 544-552.

2. Grant AP. Acute ethylene glycol poisoning treated with calcium salts. Lancet 1952; 2: 1252-1253.

3. Friedman EA, Greenberg JB, Merrill JP, Dammin GJ. Consequences of ethylene glycol poisoning: Report of four cases and review of the literature. Amer J Med 1962; 32: 891-902.

4. Ahmed MM. Ocular effects of antifreeze poisoning. Brit J Ophthal 1971; 55: 854-855.

5. Parry MF, Wallach R. Ethylene glycol poisoning. Amer J Med 1974; 57: $143-150$

6. Stokes JB, Aueron F. Prevention of organ damage in massive ethylene glycol ingestion. J A M A 1980; 243: 2065-2066.

7. BergerJR, Ayyar DR. Neurological complications of ethylene glycol intoxication: Report of a case. Arch Neurol 1981; 38: 724-726.

8. Fellman DM. Facial diplegia following ethylene glycol ingestion; Letter to the editor. Arch Neurol 1982; 39: 739-740.

9. Gordon HL, Hunter JM. Ethylene glycol poisoning: A case report. Anesthesia 1982; 37: 332-338. 